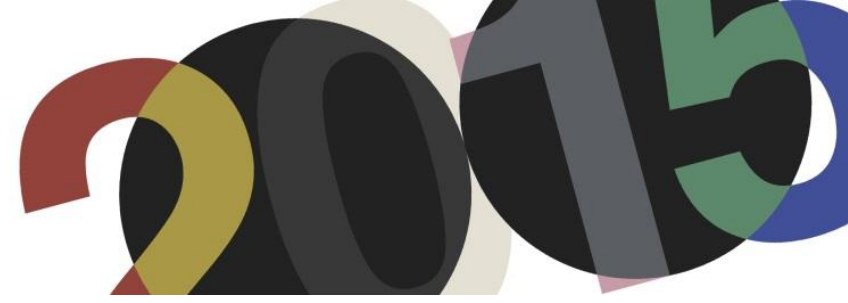

DOI: http://dx.doi.org/10.4995/LC2015.2015.810

\title{
El lugar del arte en arquitectura. Los "lieux porte-voix, porte-paroles, haut-parleurs" de Le Corbusier en su discurso del Convegno Volta, 1936
}

\section{J.L. Chacón R.}

Universidad de Los Andes. Mérida, Venezuela

\begin{abstract}
Resumen: En 1936 se celebró en Roma el Convegno Volta dedicado a la relación entre arquitectura y las artes figurativas. Entre los participantes estaba Le Corbusier quien presentó una ponencia donde claramente explica los fundamentos del lugar del arte en arquitectura, aspecto clave de su posterior Synthèse des arts.

Luego de un manifiesto sobre la Arquitectura Moderna, Le Corbusier afirma que en ocasiones excepcionales puede darse la "colaboración" entre arquitectura y arte con el fin de "aumentar el placer de los hombres". Dirige su atención a la pintura, la escultura y el diseño; y plantea como respuesta la policromía y los puntos "precisos y matemáticos" donde el artista "fuerte y digno" puede hablar y hacer sentir su discurso. Estos lugares del arte son comunicantes: "lieux porte-voix, porteparoles, haut-parleurs"; aun inexistentes entonces pero que se verán realizados años después, en la idea de la Synthèse des arts.
\end{abstract}

Abstract: In 1936 the Convegno Volta took place in Rome and it was dedicated to discuss the relationship between architecture and the figurative arts. Among the participants there was Le Corbusier, who presented a speech where he clearly establishes the fundamentals of the place of art in architecture, a key point in his later Synthèse des arts.

After a manifesto of Modern Architecture, Le Corbusier states that in certain exceptional cases there can be "collaboration" between architecture and art, with the scope of "increasing human pleasure". His attention is placed upon painting, sculpture and design; and as a response he proposes polychromy and "precise and mathematic points" where a "strong and worthy" artist can speak and let his discourse be felt. These places are communicative: "lieux porte-voix, porte-paroles, haut-parleurs". Although inexistent then, they will be materialized years later in the way of the idea of the Synthèse des arts.

Palabras clave: Arte, Arquitectura, Convegno Volta, Le Corbusier, Síntesis de las artes.

Keywords: Art, architecture, Convego Volta, Le Corbusier, Synthesis of the arts.

\section{El Convegno Volta: las relaciones de la arquitectura con las artes figurativas}

En 1936 en la Reale Accademia d'Italia de la ciudad de Roma fueron convocados artistas, arquitectos, historiadores y críticos para discutir el tema de las relaciones de la arquitectura con las artes figurativas al Convegno Volta ${ }^{1}$, evento organizado por Marcello Piacentini con el auspicio de la Fondazione Alessandro Volta. El discurso inaugural, por Romano Romanelli quien suplió a Piacentini por motivos de salud ${ }^{2}$, expresa la pretensión del congreso "el argumento [...] es muy querido a los pueblos que precian poseer una civilización" Romanelli. Haciendo referencia a la monumentalidad de Roma, antigua y -en aquel momento- fascista,

\footnotetext{
${ }^{1}$ El evento se tituló Convegno di Arti. Tema: Rapporti dell'architettura con le arti figurative, y se llevó a cabo del 25 al 31 de Octubre de 1936, en los espacios del Campidoglio de Roma.

${ }^{2}$ Piacentini intervendrá luego en el congreso con una ponencia titulada Le Tendenze dell'architettura racionalista in rapporto all'ausilio delle arti figuartive, justo antes de la de Le Corbusier. En ésta expondrá la importancia que ha tenido siempre la pintura en las edificaciones, y propone un retorno a la arquitectura monumental, la cual "exige la ayuda -para no permanecer estéril- de la pintura".

${ }^{3}$ Romanelli, Romano: "Discorso del Presidente del Convegno". En Fondazione Alessandro Volta: Convegno di Arti. Tema: Rapporti dell'architettura con le arti figurative. p.13.
} 
Romanelli sugiere el camino que deben emprender las artes luego de la crisis de finales del s.XIX; delinea así el objetivo principal de "establecer, en términos sobrios y precisos, cuales puedan ser los medios para volver a conferir eficacia a una verdadera y fecunda colaboración [entre las tres artes mayores]"4.

Entre los participantes del Convegno di Arti estuvieron José María Sert, Paul Bonatz, Marcel Denis, André Lhote, Filippo Marinetti, Mario Sironi, Gio Ponti, Ugo Ojetti, Giuseppe Pagano, entre otros. Le Corbusier fue también uno de ellos, quien participó con una ponencia titulada "Les tendance de l'architecture rationaliste en rapport avec la collaboration de la peinture et de la sculpture / L'œuvre d'art, présence insigne" generando grande polémica entre el público presente. Es un discurso donde claramente explica las razones que fundamentan el lugar del arte en arquitectura, aspecto clave para comprender su Synthèse des arts. En efecto, este discurso representa junto al artículo "Sainte Alliance des arts majeurs ou Le grand art en gésine" de 1935, los primeros textos de Le Corbusier que tratan sobre la idea de una síntesis de las artes, apoyado además en las premisas expresadas anteriormente en los años 20 en L'Esprit Nouveau ${ }^{5}$.

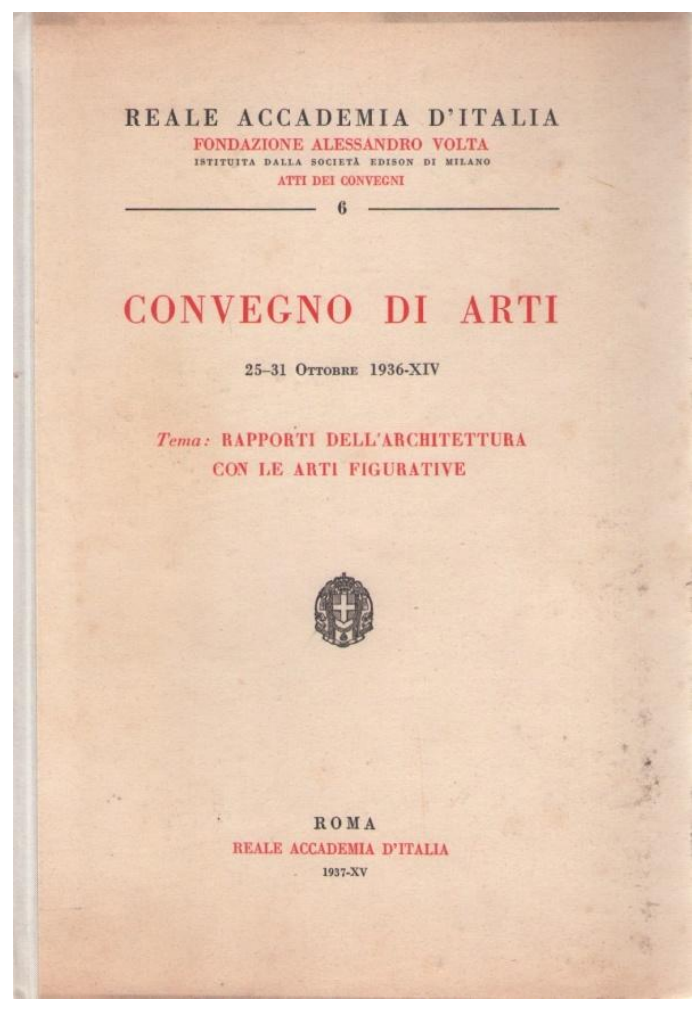

1. Portada del libro del Convegno Volta publicado por la Reale Accademia d'Italia en 1937.

Se plantea entonces realizar un análisis crítico de este discurso con el fin de resaltar tanto la valencia histórica como la estética de uno de los aspectos más importantes del pensamiento -en particular, estético- de Le Corbusier. Lo que constituyó una preocupación constante a lo largo de toda su carrera, la relación de la obra de arte en la arquitectura es un problema, aún poco tematizado por los historiadores de arquitectura y de arte en general, de gran belleza y de gran alcance, que necesita profundizarse e incluso promoverse.

\footnotetext{
${ }^{4}$ Ibidem. p.19.

${ }^{5}$ Cfr. Jornod, Naïma: "Le Corbusier ou la Synthèse des arts". En Jornod, J.P.; Jornod, N.; Sbriglio: Le Corbusier ou la synthèse des arts. p.16.
} 


\section{La Nueva Arquitectura}

La intervención de Le Corbusier en el Convegno Volta abre con la exposición de un manifiesto de la Arquitectura Moderna, en el cual se exaltan sus valores nuevos, y en especial el valor visual de la misma. Lo hace bajo el subtítulo " $L$ 'étude de la tendance qui règne au contraire dans l'architecture rationnelle d'exclure, en tant que superflu d'après une logique rigoureuse, le concours des arts figuratifs", y lo desarrolla en 23 puntos. Es un resumen sucinto de Vers une Architecture ${ }^{6}$, la obra insigne de promoción de la nueva Arquitectura Moderna, en la cual se muestran, según $\mathrm{J} o r n o d^{7}$, ya visos de la relación entre arte y arquitectura.

La pregunta con la cual introduce el problema es existencial: ornar o no ornar, decorar o no decorar, enriquecer o no enriquecer, ennoblecer o no ennoblecer; he allí el objeto que reúne arquitectos y artistas en tal evento. Su respuesta es claramente anti-académica, y contextualmente provocadora: "el olor que emana de los discursos, escritos y discusiones sobre este tema, es olor del pasado. Incienso quemado en algunas capillas" Le Corbusier $^{8}$. Ya su posición crítica -y de llamado de atención- ante el tema de discusión del congreso lo había manifestado en un telegrama que antecede su presentación oral ${ }^{9}$. Le Corbusier advierte en éste que la discusión no debe ser un retorno o un renacimiento del pasado, sino que debe más bien mirar a la nueva arquitectura, a la nueva sociedad, a la "era de la máquina".

"Es en la manifestación de las fuerzas humanas fundamentales, primarias, esenciales, que el -hombre- buscará el eje de sus verdades" Le Corbusier ${ }^{10}$. Este llamado a voltear la mirada sobre la esencia de los nuevos tiempos, permite superar un debate que se quede en "vanas decoraciones, intervenciones pictóricas o empastados plásticos". Por eso plantea la necesidad de un "examen profundo del fenómeno arquitectónico" que ayude a comprender las conquistas de los nuevos tiempos.

Para comprenderlas hay que observar a las "máquinas". Desde una pluma estilográfica hasta un dirigible Zeppelin (desde el cual escribió su intervención), todos son objetos, considerados como hechos arquitectónicos, en fin, "forrajes de los eventos sociales nuevos" 11 . De observar estos objetos (productos de la ingeniería y el diseño) "precisos, dramáticos, rigurosos" surge la nueva concepción de arquitectura, que Le Corbusier define en los términos de "formas bajo la luz" resultado de un "juego sapiente"12. Mirando lo que nadie miraba, descubre y expresa la nueva arquitectura como creación subjetiva e infinita.

Estas formas son concreciones de intensiones humanas, para ser recorridas por dentro y por fuera: "se entra, se camina, se mira; se mira procediendo mientras las formas se despliegan, se desarrollan, se combinan [...] se avecinan, se ven, nos interesan, nos paran, se aprecian, se giran alrededor, se descubre"13. He allí el "juego jugado" corbusereano: habitar la obra arquitectónica, desde y para el cuerpo humano. Este es, pues, el centro vital de la arquitectura.

\footnotetext{
${ }^{6}$ Llama la atención que este libro fuera dedicado a su amigo artista Amadeo Ozenfant, quien lo introdujo en la pintura.

${ }^{7}$ Jornod, Naïma, Op.cit. p.17.

${ }^{8}$ Le Corbusier: "Les tendance de l'architecture rationaliste en rapport avec la collaboration de la peinture et de la sculpture / L'œuvre d'art, présence insigne”. En Fondazione Alessandro Volta: Convegno di Arti. Tema: Rapporti dell'architettura con le arti figurative. Roma. p. 107. Traducción del autor (así como las demás citas).

${ }^{9}$ En tal sentido ver las páginas 102 a 107 de su discurso.

${ }^{10}$ Le Corbusier, Op.cit., p.108.

${ }^{11}$ Ibidem, p.110.

${ }^{12}$ Estos son los mismos términos utilizados en Vers une architecture.

${ }^{13}$ Ibidem, p.111.
} 
En consecuencia, lo primordial en la obra arquitectónica son el volumen y el espacio, todo lo demás es secundario. Los medios para expresarlos son la planta y la sección, la luz y la proporción. En los primeros, Le Corbusier no se detiene a explicarlos; de la luz hace un manifiesto que desemboca en el último. Por una parte, "estamos a la merced - de la luz-del sol" porque ésta tiene un efecto potente y determinante sobre las emociones psico-fisiológicas del hombre ${ }^{14}$. Por otra, las proporciones, de igual manera, se determinan según medidas, conveniencias e intenciones, afirma Le Corbusier. "Yo entraré a esta habitación por esta parte, por cuanto la sorpresa se dará de acuerdo a la sinfonía ideada por mí. Y la luz solar entrará de una manera dada y no de otra" .

No son las formas en sí a lo que se refiere el maestro suizo, sino en cuanto que son percibidas por el espectador (de arquitectura), o habitante. En tal sentido, la luz y la proporción son comprendidas como pathos, como afecciones corporales en el espectador. Para esto no hacen falta ni decoraciones ni estilos ni calificativos señala Le Corbusier, solo el "juego sapiente, correcto y magnifico", que conlleva a combinar los elementos, de modo análogo a la música tal y como si fuera una sinfonía de volúmenes y espacios.

Le Corbusier concluye esta primera parte afirmando de manera prepotente que la arquitectura no tiene en efecto necesidad de las artes. "La arquitectura es una actividad que se extiende a cada construcción sujeta a las leyes de la visión"16; es una actividad plástica que genera objetos. Por eso no ve la razón por la cual se le deban agregar las artes figurativas. Y sin embargo, luego de demostrar esto, paradójicamente procede a explicar la excepción de la regla: existen ciertas ocasiones donde la arquitectura puede "augmenter le plaisir des hommes par une collaboration exceptionnelle et magnifique avec les arts majeurs" "17. Y así entra en escena la obra de arte, como "presencia" excepcional, poderosa y sobre todo "insigne", en la nueva arquitectura.

\section{Las "presences insignes"}

¿A qué se refiere entonces Le Corbusier con artes mayores? ¿Qué es arte para él? Las artes son géneros producidos por el "espíritu de perfección" del hombre, en tanto que generan "placer" hasta conmover el corazón. Así, la literatura, el teatro, la música, la arquitectura, la escultura y la pintura son artes, expresiones humanas que logran dicho fin. No así las artes decorativas, las cuales vienen señaladas despectivamente como consecuencias del "declive de una civilización". Bajo el subtítulo L'oeuvre d'art, présense insigne, Le Corbusier explica que más allá de una diversidad (de artes), el Arte es uno, humilde y potente. He aquí otro punto clave: sólo el Arte, solo y en mayúscula, es aquel capaz de aumentar el placer de los hombres, no el decorativo ni el aplicado; el Arte, expresado en una obra, es el único que puede entrar a jugar en una "colaboración" con la arquitectura.

En primer lugar, su preocupación principal la dirige hacia la pintura y los pintores. A tal respecto, la primera propuesta que lanza es la Policromía. Basado en el hecho que "el color es expresión inmediata, espontánea de la $v i d{ }^{" 18}$. Le Corbusier expone que la policromía no es más que un elemento arquitectónico; por medio de colores (naturales) se expresa la fuerza de un muro, y se resalta. Por ello, el lugar para los colores, es decir para la pintura, son las superficies de los muros, al igual que de las puertas y ventanas.

\footnotetext{
${ }^{14}$ Cfr. Ibidem, p.112.

${ }^{15}$ Ibidem.

${ }^{16}$ Ibidem, p. 113 .

${ }^{17}$ Ibidem, p. 114.

${ }^{18}$ Ibidem, p. 115.
} 
Pero esto lo afirma luego de haberse puesto el problema que este hecho representa. Para Le Corbusier el modo tradicional de asumir esto es paliativo: "andamos de inmediato a buscar a los pintores para hacer explotar los muros que nos dan fastidio" 19 . La pintura, tales y como los frescos y murales, esconde en realidad muros y paredes, restándole el protagonismo que éstos deben tener. Aún cuando pretendan respetar la arquitectura y ponerla en valor, el peligro de la pintura es lo opuesto, y es lo que sucede a menudo. En cambio, "la policromía arquitectónica no asesina los muros, puede más bien moverlos en profundidad y clasificarlos según su importancia" ${ }^{20}$. De esta manera, la policromía no es un agregado sino una respuesta adecuada, una herramienta arquitectónica de gran poder, un "elemento mismo de la planta y la sección”.

Aparte de los muros y paredes, Le Corbusier le presta también atención, pero sin detenerse en profundidad, a las "hojas móviles" (supuestamente de puertas y ventanas), por cuanto son elementos arquitectónicos que han servido como objetos de decoración. Al respecto, rechaza violentamente la tradicional operación del fresco (o la pintura aplicada), sugiriendo que estos elementos son idóneos para ser ocupados por "pintores verdaderos, dignos de la arquitectura"21.

Por consiguiente, el pintor que colabora con el arquitecto debe entender esto, debe ser pues ser "digno y fuerte". No cualquier pintor, ni siquiera cualquiera que esté formado para eso. En defensa de ese pintor ideal, Le Corbusier le reclama su rol ante la arquitectura: “Qui es-tu? [...] Que vas-tu dire?”. Solo entonces, en esas ocasiones "excepcionales" si cumple con las exigencias de la arquitectura, le permite una respuesta: "ici vous avez la parole; parlez!"22. Solo en dichos momentos, podrá la pintura tener lugar permanente y eterno en la arquitectura $^{23}$.

En un segundo plano está la preocupación por la escultura. Para Le Corbusier, ella tendrá cabida solo si se asimila igualmente a ser elemento arquitectónico como la policromía. En la discusión se toman por descontado los detalles en cuanto a los tipos de escultura o sus características, y señala los espacios en los cuales la estatuaria puede entrar y "hablar" en ciertos puntos del espacio arquitectónico. Por eso dice "autour de l'edifice, dedans l'edifice, il est des lieux précis, lieux mathématiques, qui intégrent l'ensemble et qui sont des tribunes d'oú la voix d'un discours trouvera son écho tout autour" ${ }^{24}$. En el juego sapiente de volúmenes bajo la luz, el lugar de la escultura ocupará sutil y precisamente un "lugar matemático", como por ejemplo, el foco de una parábola o un elipse, o bien el punto de intersección de varios planos. De allí que hable de una colaboración como operación tanto sutil como precisa. Si este objetivo se logra, igualmente como a los pintores, Le Corbusier increpa a los escultores: "s'il vaut la peine que ton discours soit tenu", entonces, "entre ici, sculpteur"25. Y la escultura entrará para convertirse también en un elemento más de la arquitectura.

En paralelo al valor tridimensional de la escultura, Le Corbusier da importancia en su discurso a las molduras, por cuanto ocupan un lugar intermedio entre los muros y el espectador. Comprendidas como elementos que "diseñan los trazos de una superficie", las molduras permiten de hecho "exaltar a veces la matemática -de la

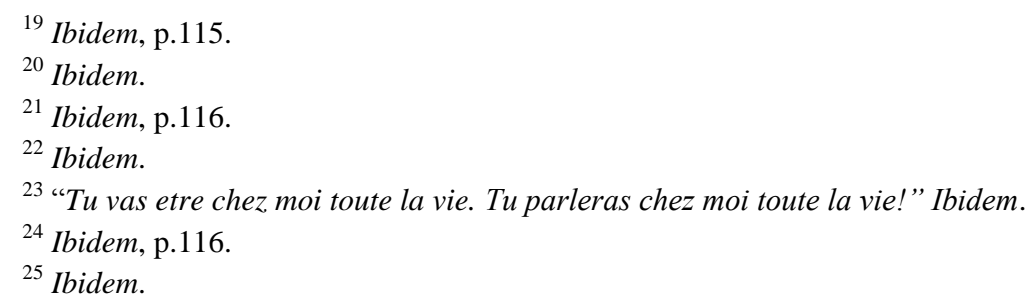


edificación- mediante el diseño riguroso con el cual se definen las superficies o volúmenes, o mediante los compartimientos a través de los cuales los multiplica"26.

\section{El lugar del Arte}

El lugar del Arte en la arquitectura, según Le Corbusier, está determinado por las intenciones arquitectónicas. En tanto que la obra de arte es una presencia insigne, ésta posee un poder particular que necesariamente dialoga, entra en sintonía, con el espacio para lograr un fin común: exaltar la percepción del espectador. Los lugares del arte en arquitectura son por tanto lugares comunicantes, "lieux porte-voix, porte-paroles, haut-parleurs" ${ }^{\text {"27 }}$. La capacidad de comunicar, para exaltar emociones, es el punto clave. De allí que Le Corbusier dirija su palabra a los pintores y les diga "Aquí tienes la palabra, ;habla!", y a los escultores "haz tu ingreso, oh escultor, si vale la pena que llegue a oírse tu voz" ${ }^{28}$. Por consiguiente, estos lugares portan y lanzan la voz, las palabras, insignes y dignas del artista y de su obra. Estos lugares potencian, no la obra en sí misma, sino las cualidades perceptivas de un espacio, resaltado por la misma. Si no es así, la obra engaña y oculta la arquitectura (y esto es precisamente lo que entiende Le Corbusier por decoración).

En esta afirmación, la arquitectura no se comprende ni como teatro, ni como fondo (inerte) que sostiene el arte; sino como fundamento geométrico y espacial de un todo. Los lugares del arte hacen parte de la matemática del plan arquitectónico. Por eso habla de ciertos puntos fijos, "puntos precisos, puntos matemáticos", en los cuales pueden aparecer las obras de arte, sean tridimensionales (esculturas o molduras) o bidimensionales (pinturas, muros policromados o paneles). Su ubicación depende del plano, es decir, de las intenciones arquitectónicas luego materializadas en el espacio. "Estos lugares matemáticos son la integral misma de la arquitectura de los tiempos nuevos, la cuya ley esencial es ser organismos palpitantes, exactos, eficaces, simples, armónicos, a efluvios lejanos, a ondas radiantes" ${ }^{\prime 29}$.

"La aventura arquitectónica de los tiempos modernos, de los nuevos tiempos es algo serio",30; por eso, la colaboración de los artistas no puede reducirse a una operación superficial. No hay cabida según Le Corbusier para los "viejos refritos" de la tradición, es decir, los frescos, los cuadros, las esculturas y las molduras ornamentales; el sentido que tuvieron antes, ya no lo tienen en los nuevos tiempos. Ni tampoco hay cabida para los 20.000 pintores y escultores desocupados de París (a los cuales se refiere constantemente), formados seguramente según la tradición Beaux Arts, como decoradores, y que no consiguen lugar en la nueva arquitectura. Su condición misma de pintor, le hace reclamar vigorosamente mayor profundidad, mayor comprensión, mayor dialogo.

Estos lugares en la arquitectura no existen para el Le Corbusier de 1936; ellos son parte de los tiempos nuevos, aún por crear, con inventiva y coraje más allá de las costumbres del pasado. Aunque ya en el pabellón del Esprit Nouveau de 1925 se asomaba una primera experimentación, será después de la segunda guerra donde desarrollará y materializará estas ideas en obra. Esta postura del año 36 está llena de optimismo, del mismo que lo acompañó siempre: "tout peut être raconté, montré, bâti en apparitions sensationelles du monde, de l'immense monde inconnu ${ }^{\text {"31 }}$. Es con esta actitud que podrá incluir las nuevas formas de arte en la arquitectura,

\footnotetext{
${ }^{26}$ Ibidem, p.117.

${ }^{27}$ Ibidem, p. 116.

${ }^{28}$ Ibidem, p.116-117.

${ }^{29}$ Ibidem, p. 116.

${ }^{30}$ Ibidem, p. 117 .

${ }^{31}$ Ibidem, p.118.
} 
como por ejemplo el cine o el fotomontaje. En el cine, dice Le Corbusier, "la Grande Nature est ouverte désormais" ",2 el cual sustituye el "teatro de pose". El fotomontaje, ejecutado directamente sobre el muro, puede por otra parte "demostrar públicamente, probar, revelar, instruir". Son modalidades nuevas que brindan bondades y posibilidades que superan la imaginación de entonces.

\section{Comentarios y valorizaciones}

Luego de este breve e intenso manifiesto, Le Corbusier viene, en palabras de Giuseppe Pagano, discutido y adversado por dos arquitectos, mientras que es defendido por dos literatos; Pagano mismo se reparte entre las dos posiciones ${ }^{33}$. En realidad, Le Corbusier recibe la simpatía de la mayoría por su capacidad de "agudo y hábil propagandista del espíritu nuevo" Pagano ${ }^{34}$, pero es contestado por su visión radical de la arquitectura y en particular por la relación anti-académica con las artes.

Bonatz ${ }^{35}$ lo acusa de sugerir un "culto exagerado del individuo" aún cuando promulga "servir las necesidades de los usuarios". En cuanto a la unión de las artes con la arquitectura, afirma en oposición que "nunca jugaron el rol de ornamentos subordinados. Han sido siempre parejas iguales ${ }^{\$ 36}$. Husarski ${ }^{37}$ lo señala de iconoclasta; y Hautecoeur ${ }^{38}$ de abstraccionista (postula un ideal universal cuando la arquitectura es sumisa a condiciones contingentes). Severini ${ }^{39}$ es quien pone en tela de juicio sus afirmaciones "civilizatorias". Luego de hacer un breve bosquejo histórico de la relación entre arquitecto y artista, Severini asiente el hecho de estar ante una nueva época pero que el arte debe recomenzar "hacia nuevos destinos ligados sin embargo a la tradición" Dudok $^{41}$ critica la actitud de rechazar los logros obtenidos por artistas y arquitectos de antes, sugiriendo que ya, entre otras cosas, se ha logrado una síntesis de las artes. Igualmente Calza Bini ${ }^{42}$, en oposición a la propuesta corbusereana, reafirma "no renunciar nunca al aporte de luz y fuerza expresiva de las artes figurativas" en Italia como en el resto del mundo.

\footnotetext{
${ }^{32}$ Ibidem.

${ }^{33}$ Cfr. Fondazione Alessandro Volta: Op.cit., p.143.

${ }^{34}$ Ibidem, p. 144.

${ }^{35}$ Paul Bonatz, arquitecto alemán, con diversas obras proyectadas principalmente en Stuttgart.

${ }^{36}$ Ibidem, pp. 130-131.

${ }^{37}$ Vaslav Husarki, pintor y decorador polaco, docente y editor de revista de arte.

${ }^{38}$ Louis Hatecoeur, conservador y académico francés, con cargos en el Museo del Louvre y de Luxemburgo, y con diversos escritos sobre Bellas Artes.

${ }^{39}$ Gino Severini, pintor italiano, fundador junto a Marinetti, Boccioni, Carrà y Balla del movimiento futurista.

${ }^{40}$ Ibidem, p. 136.

${ }^{41}$ Willem. H. Dudok, arquitecto holandés, con obras en Amsterdam y Rotterdam.

${ }^{42}$ Alberto Calza Bini, arquitecto y urbanista italiano, académico y líder del Fascismo, con obras en Roma, Bari, Bolzano, entre otras.

${ }^{43}$ Ibidem, p. 143.
} 


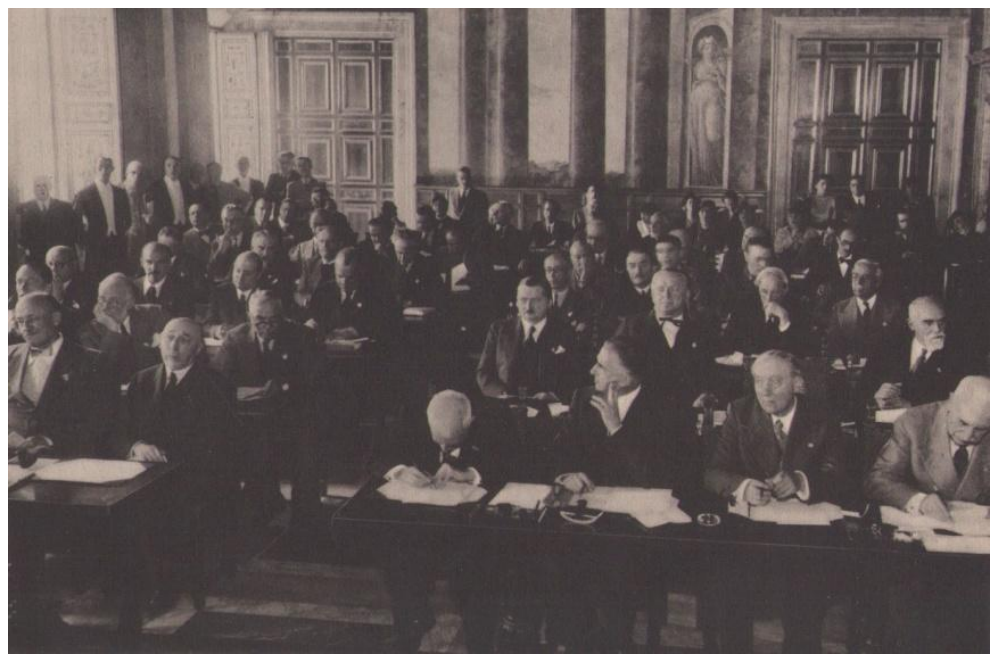

2. Fotografía del grupo de participantes en el Convegno Volta en 1936.

Históricamente, el tiempo le dará la razón al arquitecto Jeanneret. Éste se presenta pues como un visionario que irrumpe las intenciones del Convegno di Arti, aún ancladas en la tradición. Aún sin tener obras construidas que sustenten su pensamiento, Le Corbusier proyecta una mirada asombrosa, que se verá realizada muchos años después, en Chandigarh, Bruselas, Ronchamp y La Tourette, por ejemplo. Y conseguirá además una numerosa cantidad de adeptos, a través de los brazos comunicantes de los CIAM, que se adherirán a estas ideas y conformarán todo un movimiento $^{44}$ que vendrá llamado Synthèse des arts. Ejemplo de ello se encuentran ubicados en todas partes del mundo, como en Italia, Francia, Brasil, Venezuela ${ }^{45}$, Estados Unidos, entre otros.

El concepto de Síntesis de las artes lo cautivará y usará más a menudo después de la guerra; vendrá divulgado y aplicado sobre todo por ese rasgo característico de multidisciplinariedad que le es propio. Según Jornod la síntesis de las artes de Le Corbusier "se presenta como una colaboración entre diversas disciplinas artísticas. Afirmando que el arte nunca decora, el considera de hecho que la obra de arte es una presencia que se compara a un 'huesped o visitante' dentro de una arquitectura que nos habla” Jornod ${ }^{46}$. En esta concepción, “cada obra tiene su rol", cada disciplina es autónoma y posee su propia fuerza. Aunque está anclada en los mismos intereses que perseguía el movimiento Arts \& Crafts de William Morris, e influenciada por los logros de las Vanguardias artísticas, tales y como el Neoplasticismo y el Constructivismo en particular, la posición corbusereana de síntesis es distinta a la integración "bauhaussiana", planteada por Gropius. Según von Moos "su problema era cómo lograr una consonancia básica entre las diversas manifestaciones de la creatividad y permitir que el edificio, la pintura y la escultura pudieran aún permanecer autónomos dentro de la totalidad" von Moos ${ }^{47}$. El objetivo de este ideal era lograr una "Unidad" en un producto procedente de diversas disciplinas; "un tal concepto -afirma de hecho Jornod- correspondería a un objetivo absoluto"48. La idea de "Unidad" por medio de la “colaboración”, además de poseer resonancias con la Gesamtkunstwerk, representa la inserción del carácter

\footnotetext{
${ }^{44}$ Más que movimiento fue una tendencia, la cual tuvo gran resonancia en Latinoamérica y en Norteamérica.

${ }^{45}$ Cabe mencionar la Ciudad Universitaria de Caracas (1949-1970), proyectada por Carlos Raúl Villanueva, la cual representa "uno de los ejemplos mejor realizados de la llamada Síntesis de las artes" Chacón.

${ }^{46}$ Jornod, Op.cit., p.19.

${ }^{47}$ von Moos, Stanislaus: Le Corbusier. Elements of a Synthesis, p. 280.

${ }^{48}$ Jornod, Op.cit., p. : 18.
} 
“ideal”, propiamente moderno, en la relación histórica entre arte y arquitectura. La actitud moderna, como afirma una investigación del autor, se manifiesta en obras donde "el arte se integra como un ideal a priori a la arquitectura; la idea se coloca antes de la obra, siendo la integración una confirmación de la operación" Chacón ${ }^{49}$. Pero esta integración idealista pretendía ser "un modo de crear una sociedad nueva y radicalmente mejor de aquella precedente" ${ }^{\text {,50. }}$

Aún cuando el ideal de Síntesis de las artes se agotó a finales de los años 60, se evidencian resonancias de la misma en obras contemporáneas, las cuales, lejos de estar adheridas a este ideal de síntesis, transitan por un mismo camino experimental de colaboración entre arte y arquitectura ${ }^{51}$.

Estéticamente, el lugar del arte que propone Le Corbusier en el Convegno Volta de 1936 se apoya en tres fundamentos interrelacionados entre sí: el juego, la disciplina y la investigación. O lo que sería en otras palabras, estos son los "puntos" teóricos que este discurso presenta, pero que a la larga fundamentarán la futura Synthèse des arts.

En primer lugar, la arquitectura para Le Corbusier es una actividad plástica, en la cual los volúmenes y la luz son los protagonistas de un "juego" intencional y libre. Por tanto, la arquitectura es en efecto Arte, así como son la pintura y la escultura. En este Arte, la obra de arte será considerada un elemento primordial, el cual ocupará un lugar esencial - "excepcional” decía el maestro- del juego arquitectónico. Ese lugar permitirá que la obra hable, grite, comunique su sentido y valor, para que pueda en fin lograr la exaltación emocional del habitante. La síntesis entre arte y arquitectura por medio del sapiente juego corbusereano generará entonces esos lugares "porte-voix, porte-paroles, haut-parleurs".

En segundo lugar, la arquitectura es una disciplina, es decir, un oficio que Le Corbusier ejercía diariamente, en estrecha relación con la pintura y la escritura. Es sabido que las mañanas de este "homme du letres" las dedicaba al ejercicio de la pintura, y las tardes a la arquitectura (las noches, tal vez a la escritura). "Aún cuando Le Corbusier había cultivado la imagen del artista como un ingeniero sensible, más tarde llegó a pensar su pintura como una actividad fundamentalmente privada - un dialogo intimo con los dramas de la forma y el color y una lucha con memorias, miedos y alegrías emergentes del subconsciente" von Moos ${ }^{52}$. Para él ambas disciplinas mantuvieron siempre su autonomía; se ve la diferencia entre el Le Corbusier-pintor y el Le Corbusier-arquitecto. Sin embargo, la experiencia de ambas demuestra una inter-relación entre ellas, la una se permea en la otra. Von Moos utiliza el término "displacement of concepts" para referirse a esta permeabilidad: "figuras individuales o

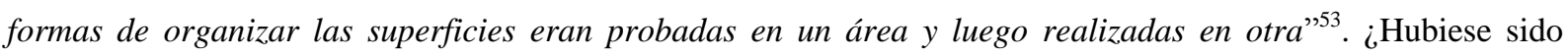
posible haber alcanzado tales logros sin esta capacidad multidisciplinaria? La idea de la Synthèse des arts es también la formulación existencial de un síntesis de vida, en este caso, de vida del hombre moderno.

Y en tercer lugar, toda la preocupación que tuvo Le Corbusier por la relación entre arte y arquitectura, se comprende como un intenso y extenso proceso de investigación. Desde sus inicios en el purismo, pasando por la formulación de los objets a reaction poétique, hasta sus obras maestras en Ronchamp o Chandigarh, se demuestra una constante reflexión que va de la práctica a la teoría, y viceversa. "Le Corbusier era un artista que creía en el dibujo y a quien gustaba presentar sus ideas en claras formulas gráficas" afirma von Moos; y tenía

\footnotetext{
${ }^{49}$ Chacón R., José Luis: Il rapporto tra arte e architettura: un «cerchio non chiuso». p.304.

${ }^{50}$ Ibidem.

51 Ver el Capítulo I, sección 1.1, de la Primera Parte APERTURA. UNO SGUARDO CONTEMPORANEO (ALLA SOGLIA DEL SECONDO MILLENNIO), de la mencionada tesis del autor.

52 von Moos, Op.cit., p.282.

${ }^{53}$ Ibidem, p. 284.
} 
una obsesión por el dibujo "como el médium por medio del cual ver, medir, y entender su contexto" "54. Su propuesta de "colaboración" entre arquitecto y artista, es pues un ideal surgido de la experiencia pero desarrollado como hecho ideológico, una práctica que se convierte en teoría y que luego vuelve otra vez a la práctica. Por consiguiente, "Les tendance de l'architecture rationaliste en rapport avec la collaboration de la peinture et de la sculpture / L'œuvre d'art, présence insigne" se comprende como parte de una investigación "proyectual" " : una teorización de las experiencias iniciales, que luego materializará en las obras maestras de su madurez. Este proceso de investigación resumido bajo el término Synthèse des arts es algo que Jeanneret lleva a cabo a lo largo de toda su carrera; es una verdadera y propia recherche patiente hacia una síntesis entre arquitectura, las artes y la vida.

No es difícil hacer por ultimo notar la correspondencia entre estos tres puntos y su vida. Desde los explosivos inicios hasta su misteriosa muerte, la vida de Le Corbusier transcurre como un verdadero "service de la poésie", dedicado a veces a la machine, otras al Angle droit, en algunas ocasiones como électroniqué, pero sobre todo, constantemente indicible. La fuerza de su poética, tanto desde la perspectiva histórica como estética, es aún inagotable.

"Art.

L'art: expressions de l'esprit, de la pensée, de la conscience [...]

Démarche urgente: reprise contact avec l'échelle humaine [...]

Les Artistes.

Médiums: Ils manifestent en signes synthétiques compréhensibles et beaux, le torrent des évènements: homme et nature, homme et destin, -l'âme humanine [...]

Durée: La grande eloquence peut être passagère ou éternelle. Nul ne peut le fixer d'avance. Ne será éternel que ce qui a d'abord été vivant, palpitant, vrai, d'aujourd'hui" Le Corbusier ${ }^{56}$.

Así contestaba, sintéticamente, el maestro suizo ante sus interlocutores del Convegno Volta, y se marchaba.

\footnotetext{
${ }^{54}$ Ibidem, p.296.

${ }^{55}$ Ver el artículo del autor "Bases teóricas del proyecto como investigación en la enseñanza universitaria de arquitectura. Propuesta y ejemplo de implementación en la Escuela de Arquitectura de la ULA“.

${ }^{56}$ Le Corbusier, Op.cit., p.146.
} 


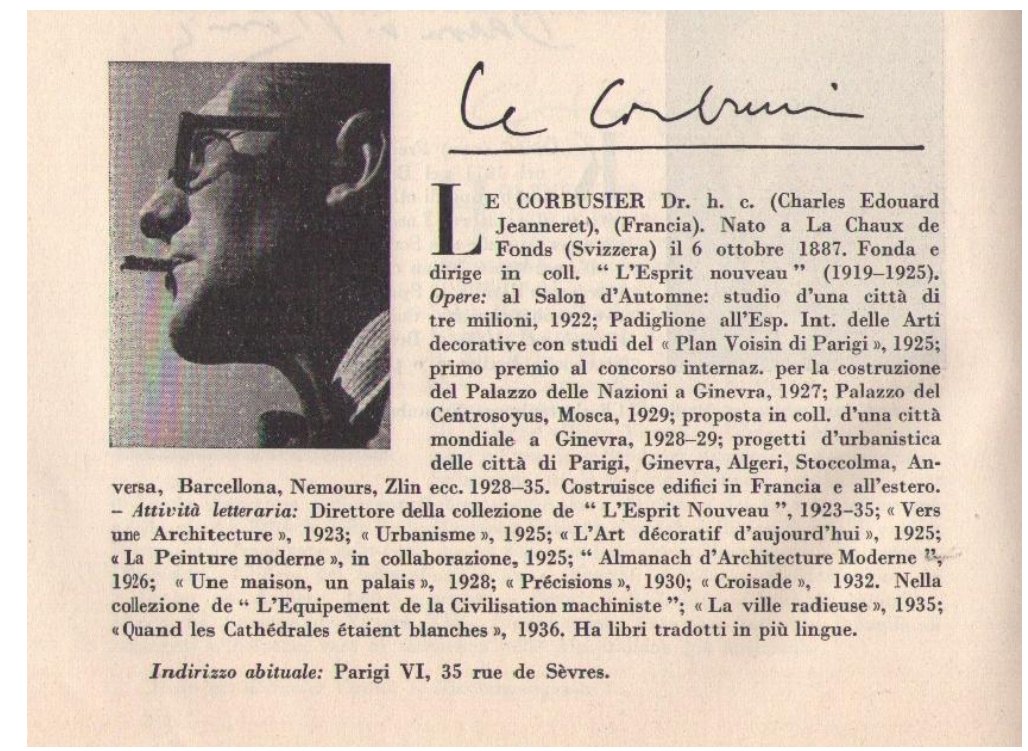

3. Ficha técnica de Le Corbusier así como aparece en la publicación.

\section{Agradecimiento}

Al Prof. Federico Brunetti, del Politecnico di Milano, por su constante apoyo, humano y académico.

\section{Créditos de las imágenes}

1 y 3. Libro propiedad del autor.

2. Fotografía en el libro, p.2.

\section{Referencias bibliográficas}

Chacón R., José Luis: Il rapporto tra arte e architettura: un «cerchio non chiuso». Tutor: Daniele Vitale. Tesis de doctorado. Milán: Politecnico di Milano, 2009.

: "Bases teóricas del proyecto como investigación en la enseñanza universitaria de arquitectura. Propuesta y ejemplo de implementación en la Escuela de Arquitectura de la ULA“. En Revista M. Volumen 10 $\mathrm{N}^{\circ}$ 2, Julio-Diciembre 2013. Bucaramanga, Colombia: Facultad de Arquitectura. Universidad Santo Tomás. pp. 6-21.

Fondazione Alessandro Volta: Convegno di Arti. Tema: Rapporti dell'architettura con le arti figurative. Roma: Reale Accademia d'Italia, 1937.

Jornod, J.P.; Jornod, N.; Sbriglio: Le Corbusier ou la synthèse des arts. Catálogo de la exposición. Milano: Skira Editore, 2006.

Le Corbusier: "Les tendance de l'architecture rationaliste en rapport avec la collaboration de la peinture et de la sculpture / L'œuvre d'art, présence insigne”. En Fondazione Alessandro Volta: Convegno di Arti. Tema: Rapporti dell'architettura con le arti figurative. Roma: Reale Accademia d'Italia, 1937. pp. 107-119.

: Hacia una arquitectura. $2^{\circ}$ Edición. Traducción de Luis A. Romero. Buenos Aires: Edit. “El Distribuidor Americano", 1939.

von Moos, Stanislaus: Le Corbusier. Elements of a Synthesis. Cambridge, Massachusetts: The MIT Press, 1979. 